Salle, B. \& Hedinger, C. (1970) Gonadal histology in children with male pseudohermaphroditism, and mixed gonadal dysgenesis. Acta endocrinologica scandinavica, 64, 211.

TAUB, J. (1954) Malignant testicular tumour, cryptorchidism and polyorchidism in a pseudohermaphrodite. Journal of Urology, 71, 475.

Vaughn, J. \& Gonzales-Angulo, A. (1961) True hermaphrodite with ovarian tumour. Journal of Urology, 86, 776.

Postgraduate Medical Journal (April 1975) 51, 255-257.

\title{
An unusual case of spontaneous bacterial myositis
}

\author{
R. H. P. Williams \\ F.R.C.S. \\ P. THOMAS \\ M.R.C.P.
}

University Hospital of Wales, Heath Park, Cardiff

\begin{abstract}
Summary
A further report of spontaneous bacterial myositis occurring in the British Isles is recorded. The case is unusual because both calf muscle compartments were simultaneously affected, and unique in that surgical decompression was required to prevent impending limb ischaemia.
\end{abstract}

BACTERIAL myositis rarely occurs among the indigenous population of temperate countries. In an account from Boston all three patients had recently arrived from tropical countries (Levin, Gardner and Waldvogel, 1971). Nevertheless, four fatal cases were seen in the post-mortem room of Addenbrookes Hospital in 1951-56 (Barrett and Gresham, 1958), a further case was recorded in California in 1964 (Altrocchi, 1971) and more recently its occurrence in a Londoner of Irish extraction has been reported (Rogers, 1973).

In contrast bacterial myositis accounts for 3-4\% of all surgical admissions in certain tropical areas (Horn and Masters, 1968).

The following case is considered worth reporting because of certain unusual features which may shed further light on the aetiology of this condition.

\section{Case report}

A 30-year-old unmarried mother of two children was admitted to hospital as an emergency. Four hours before admission she suddenly developed pain behind her left ankle which rapidly spread to the calf muscles of that leg. A few minutes later the right ankle became painful, followed by radiation of pain to the right calf. The pain rapidly became severe and she noted increasing swelling in both calves. There

Correspondence: Mr R. H. P. Williams, University Hospital of Wales, Heath Park, Cardiff. was no preceding history of trauma or of selfinjection, although she occasionally probed with a needle small septic spots on her legs and arms. Two days before admission she had danced barefoot on a local beach known to be contaminated with sewage. She suffered from epilepsy but was erratic in taking her medication. She had, on three occasions, been admitted to hospital with drug overdosage. She was not taking the contraceptive pill.

The patient was an unkempt and poorly nourished woman, temperature $37^{\circ} \mathrm{C}$, pulse 84 beats/min. Both calves were hot, tender and swollen. There were small bruises around both knee joints, a small pustule was present on the medial aspect of the right knee and numerous petechial haemorrhages over the dorsum of both feet (Fig. 1). The lower limb pulses were readily palpable and there was no venous engorgement. Both knee joints were held rigidly in $<30^{\circ}$ of flexion and movement at either knee or ankle joint produced severe calf pain. No effusion could be detected in either knee joint and the regional nodes were not enlarged. There was hypoaesthesia in both legs, from the mid-calf level which was more marked distally.

Investigations at this time: haemoglobin, $12.4 \mathrm{~g} /$ $100 \mathrm{ml}$; white cell count, $8900 / \mathrm{mm}^{3}$ with a normal differential; ESR, $19 \mathrm{~mm}$ in the first hour (Westergren); an ECG and chest X-ray showed no abnormality. A provisional diagnosis of bilateral calf vein thrombosis was made.

Over the next few hours, signs of arterial insufficiency began to appear. Skin pallor, venous guttering and anaesthesia developed in both feet, the calf swelling increased and became more tense but there was no skin oedema. Aspiration of the knee joint did not produce any fluid and arthrograms excluded the possibility of a ruptured Baker's cyst. It became 


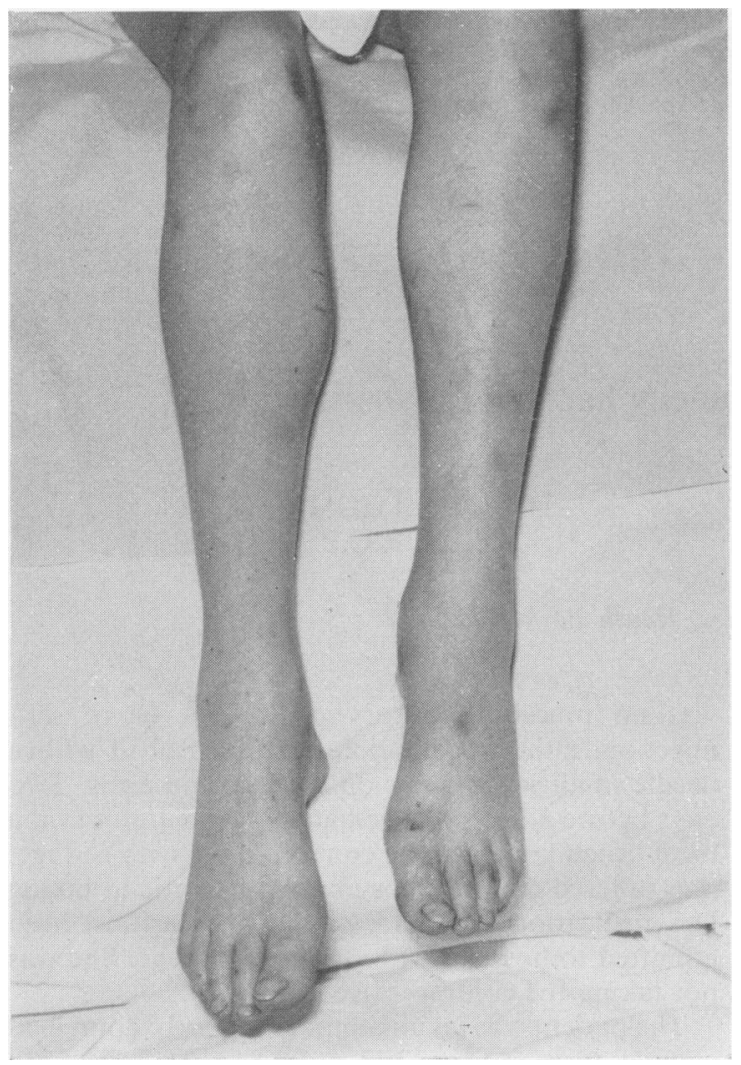

Fig. 1.

clear that the increasing sub-fascial pressure was endangering the viability of both lower limbs. Benzyl penicillin ( 3 million units/4 hr) was administered and bilateral calf fasciotomy undertaken.

At operation, oedematous muscle bulged through both fasciotomy incisions and gas bubbles were seen in the intermuscular planes suggesting a diagnosis of clostridial myositis. Swabs were taken for bacteriological investigation, and the soleus muscle was biopsied. A Gram-stained preparation revealed Gram-positive cocci but no clostridia. Culture later produced a growth of Staphylococcus aureus, phage typing of which was technically unsuccessful. Following this finding cloxacillin $(500 \mathrm{mg} / 4 \mathrm{hr})$ was added to the benzyl penicillin.

Subsequently, supporting biochemical evidence of muscle damage was received, the serum aldolase was elevated $(66 \mathrm{iu} / \mathrm{l})$ as was the creatinine phosphokinase (3180 iu/l), the SGOT (250 iu/l), the SGPT (180 iu/l) and the SHBD (778 iu/l). The total and differential serum proteins were within the normal range but both the IgG and the $\operatorname{IgA}$ fractions were initially depressed $(5.3 \mathrm{~g} / 1$ and $0.84 \mathrm{~g} / 1$ respectively). The serum urea and electrolytes, bilirubin, calcium and phosphorus were within normal limits. Later, viral agglutinins, blood culture, anti-nuclear factor, DAT, Coombs' test, WR, Kahn and RPCF tests were all negative. The muscle biopsy showed nonspecific changes of acute inflammation. A spiking postoperative pyrexia did not settle until the tenth day. The erythrocyte sedimentation rate which had risen to 67 postoperatively, returned to normal at about this time. On the fourteenth postoperative day, split-skin grafting of the fascial defect was successfully undertaken. At the time of discharge from hospital, full active movements had returned to both lower limbs and there was no residual sensory deficit.

\section{Discussion}

The pre-operative diagnosis in this case was that of greatly increased tension in the involved muscle compartments necessitating a fasciotomy to alleviate impending ischaemic changes. Our tentative operative diagnosis of bacterial myositis was then confirmed by subsequent bacteriological examination.

The characteristic onset is of a sub-acute illness with moderate muscle pain preceding fever and abscess formation by several days to weeks but occasionally it may begin as an acute toxic illness (Levin et al., 1971) and rarely as a rapidly progressive lifethreatening situation. Even in those cases which progress to localized abscess formation, fluctuation is not usually elicited at the initial presentation (Levin et al., 1971; Rogers, 1973), the absence of pus in this case may well be attributed to the early surgical intervention and administration of appropriate antibiotics. A review of the literature has failed to reveal any other case in which decompression of the muscle compartment because of impending ischaemia was necessary. This seemingly virulent presentation of the condition may also account for the marked elevation of the serum level of enzymes present in muscle, which, despite evident muscle destruction, generally remain within normal limits (Levin et al., 1971).

The high incidence of this condition in certain tropical countries has never been adequately explained. It does not appear to be related to any racial or social factor (Robin, 1961) and there is no evidence that sex, age, walking barefoot, heredity, bacteriophage type of Staphylococcus, or host defence reaction to bacteria play any significant role (Marcus and Foster, 1968; Horn and Master, 1968). Similarly, no supporting evidence could be found for an association with syphilis or leptospirosis (Foster, 1965), filariasis, ankylostomiasis, malaria or sickle-cell anaemia (Burkitt, 1947). The frequency of multiple muscle abscesses (30-40\%) strongly suggests an initiating bacteraemia, the rarity of positive blood cultures, less than $5 \%$, indicating that the bacteraemia occurs early in the illness and is not sustained 
(Levin et al., 1971). Although the most frequently encountered organism is Staph. aureus (Foster, 1965), skeletal muscle in temperate climates seems to be resistant to bacterial colonization even in the presence of an overwhelming staphyloccal septicaemia. Faber et al. (1960), found no skeletal muscle abscesses on post-mortem examination of 201 cases of fatal staphylococcal septicaemia. Miyake (1904) showed that intravenous injection of sublethal doses of Staph. aureus into rabbits would only produce muscle abscesses if the muscle was first traumatized. Ashken and Cotton (1963), presented supporting evidence for their hypothesis that muscle 'haematomas', produced by repetitive minor trauma in the presence of sub-clinical scurvy, may become infected in the presence of a bacteraemia and produce muscle abscesses. This case report seems to add further weight to their hypothesis; the patient was noticeably under-nourished, there was evidence of recent minor trauma to both legs and she may well have initiated a staphylococcal bacteraemia by her unusual habit of probing small septic spots on her legs with a needle.

\section{Acknowledgments}

We thank Dr L. Davidson and Mr J. L. Craven for their advice and encouragement.

\section{References}

Altrocchi, P.H. (1971) Spontaneous bacterial myositis. Journal of the American Medical Association, 217, 819.

Ashken, M.H. \& CotTon, R.E. (1963) Tropical skeletal muscle abscesses (Pyomyositis Tropicans). British Journal of Surgery, 50, 846.

BarRetT, A.M. \& Gresham, G.A. (1958) Acute streptococcal myositis. Lancet, i, 347.

BuRkITT, R.T. (1947) Tropical pyomyositis. Journal of Tropical Medicine and Hygiene, 50, 71.

Faber, V., Jessen, O., Rosendal, K. \& Eriksen, K.R. (1960) Staphylococcal bacteraemia. Clinical and bacteriological observations in 201 cases. British Medical Journal, ii, 1832.

FosTER, W.D. (1965) Bacteriology of tropical pyomyositis in Uganda. Journal of Hygiene, 63, 517.

Horn, C.V. \& MASTER, S. (1968) Pyomyositis tropicans in Uganda. East African Medical Journal, 45, 463.

Levin, M.J., Gardner, P. \& Waldvogel, F.A. (1971) An unusual infection due to Staphylococcus aureus. New England Journal of Medicine, 284, 196.

MARCuS, R.T. \& Foster, W.D. (1968) Observations on the clinical features, aetiology and geographical distribution of pyomyositis in East Africa. East African Medical Journal, 45, 1967.

MiYAKE, H. (1904) Beiträge zur Kenntnis des Bothriocephalus liguloides. Mitteilungen aus den Grenzgebieten der Medizin und Chirurgie, 13, 155.

RoBIN, G.C. (1961) Tropical myositis in Malaya. Journal of Tropical Medicine and Hygiene, 64, 288.

Rogers, D.W. (1973) Pyomyositis in London. British Medical Journal, iii, 679.

\title{
A case of sarcoidosis in a Chinese woman
}

\author{
Y. Y. ONG \\ A.M., M.B., M.R.A.C.P., M.Med. \\ C. H. CHEW \\ A.M., M.B., F.R.C.P. \\ S. C. ChIANG \\ M.B.B.S., D.Path. D.C.P.
}

Tan Tock Seng Hospital, Unit 4 and Outram Road General Hospital, Singapore

\begin{abstract}
Summary
A case of sarcoidosis in a Chinese woman presenting with hilar lymphadenopathy is described. In addition, there were neurological features, a depressed tuberculin test and a positive Kreim test. The condition is rare in the Chinese.
\end{abstract}

SARCoIDosis is a systemic granulomatous disease of undetermined aetiology and pathogenesis. The condition was first recognized by Hutchinson, who published a clinical description of one case in 1875 and

Correspondence: Dr Ong Yong Yau, Tan Tock Seng Hospital, Moulmein Road, Singapore 11. of two others in 1898. Boeck was the first to describe, in 1899 , the histological characteristics of the skin lesions that have since come to be associated with his name as Boeck's sarcoid (Hsing, 1964). Chapman (1955) stated that the Chinese people in Taiwan and overseas are regarded to a very large degree to be exempted from the disease. It appears that sarcoidosis is extremely rare in South East Asia and in Singapore in particular ( $\mathrm{Da}$ Costa, 1973). Japan is the only Asian country in which a sizable number of cases of sarcoidosis have been observed.

Probably the first proved case of sarcoidosis among the Chinese was reported by Hsing (1964). 